\title{
A Study of the Dispatching Order System to Support Module Structured Production System for the Demand Synchronized Production"
}

\author{
Kuniaki TANAKA ${ }^{* *}$, Masashi KURAHASHI ${ }^{* *}$, Nobuhiro HAYASHI ${ }^{* *}$ \\ Shinya INAO ${ }^{* *}$, Hironori HIBINO ${ }^{* * *}$ and Yoshiro FUKUDA ${ }^{* * * *}$ \\ ${ }^{* *}$ OMRON Corporation, \\ 2-2-1, Nishikusatsu, Kusatsu, Shiga, 525-0035, Japan \\ E-mail: kuniaki_tanaka@omron.co.jp \\ ***Technical Research Institute, Japan Society for the Promotion of Machine Industry, \\ 1-1-12, Hachiman-cho, Higashi-kurume, Tokyo, 203-0042, Japan \\ ${ }^{* * * *}$ Faculty of Engineering and Design, Hosei University, \\ 2-17-1, Fujimi, Chioyoda-ku, Tokyo, 102-8160, Japan
}

\begin{abstract}
The module structured production systems that aim for the demand-synchronized production has a function and composition for high-variety low-volume production. However, an efficient dispatching to manufacturing lines is a problem to be solved. Two requirements are necessary for the dispatching order system to solve this problem. The first requirement is that production order must be decided with parameters of evaluation values that affect efficiency. For quick response to actual orders and variable conditions of manufacturing lines, deciding a production order with short processing time would be essential. And the second requirement is to decide a production order in short time by grasping condition changes of actual orders and variable conditions of manufacturing lines in real time. In this paper, we propose a configuration and operation systems that efficiently dispatch orders by grasping actual conditions of manufacturing lines in real time for meeting customers' various demands. Effectiveness of the system is verified with examples.
\end{abstract}

Key words: Demand Synchronized Production, Module Structured Production System, Production Planning, Dispatching System, Production Line Operating

\section{Introduction}

Recently, customers' needs have become diversified because of individualism and stronger "only one" orientation. In addition, new social needs such as minimizing environmental impact, rise of security and safety have been expanded. In order to respond to these needs, stronger performance for expansion of product types in the manufacturing industries and success competition of the intense cost are essential with the rise of newly industrializing countries such as BRICs and VISTA. In the viewpoint of corporate value management, cash flow has become more important as a management index. Establishment of a production system responding to this tendency is seriously required in the manufacturing industries.

To respond to these targets, a production system, which produces and supplies various products flexibly at low cost meeting changes of demand, is needed. However, it is difficult 
to control production performance for the changes of demand while executing optimum assignment of production facilities and operators in general. Until now, by ameliorating production management methods including the levelized production and inventory control, several approaches for effective production have been made in accordance with production performance while having a delay in response to a change of demand.

Under such background, to solve contradicted issues such as expansion of product types and cash flow management, establishment of a new production system, demand-synchronized production system, is required. As a solution, we executed actions to improve flexibility of manufacturing lines and production facilities by proposing a module structured production system ${ }^{(1)}$. Establishment of a production execution method responding to condition changes in the market and factory floors, several researches have been additionally made ${ }^{(2)}$.

In this paper, we propose a dispatching order system enabling effective order dispatching to manufacturing lines and facilities responding to various changes of demands with the Module Structured Production System (MSPS) ${ }^{(1)}$ for producing the industrial control components. The effectiveness of the system is verified.

Based on our research in an industrial component vender, half of number of the order is general-purpose components, and the remainder is customizing components. The more than half is within several days in the delivery date of the order, and half of the number of the remainder is ahead for one week or more. Therefore, there is product stock longer than about the half month. Then, the target of the synchronous demand production system is to adjust the product stock to 0.1 months or less, and to adjust the manufacturing lead-time to several days.

\section{Module Structured Production System (MSPS)}

\subsection{Definition and Configuration of the System}

Recently, there have been many proposals of modular production systems and cellar production systems offered for better flexibility, scalability, and reconfigurability ${ }^{(3)-(5)}$. The Module Structured Production System (MSPS) we propose in this paper as a base of the dispatching order system is also targeting better flexibility, scalability, and reconfigurability. MSPS consists of multiple manufacturing lines and an execution system. The manufacturing lines are comprised of several production cells, which consist of function units. The manufacturing lines consist of process groups called multiple production cells that are essential to commercialize products, an essential components of MSPS. At each manufacturing line, materials are loaded into the production cell, which handles the first process, and by working and assembling them through a series of the production cells, a finished product is put through the last production cell.

Each production cell receives a work in process (WIP) derived from the previous production cell. After adding elemental operations such as processings, assemblies, inspections, and packaging required at this particular production cell to WIP, the WIPs are transferred to the next production cell. The production cells consist of one or several function unit(s). Figure 1 shows the structure of MSPS. Figure 2 shows an example of MSPS for mounting and inspecting some electronic materials on a Printed Circuit Board (PCB).

The production cell comprises of combination of several function units. Each function unit can be added or removed individually. Each function unit can be changed and set processing procedure in the cell and attributes that define assembly conditions. When changing the combination of the function units by simply adding or removing the function unit (not requiring special settings), the functions of the cell and line are changed into suitable functions such as contents of processings, assemblies, and 
inspections. Figure 3 shows a structural image we propose.

MSPS is an on-site information system, which combines information transmitting function and functions required for production execution such as the production history management, the process condition management, the cell and line operation management, and the product quality management. The proposed dispatching order system is built in as one function of the MSPS execution system. Principally, it consists of a server, which has interface with key systems and PC-based client terminals situated at each manufacturing line. The client terminal is located on each production cell. The client terminal is connected through each production cell, which releases required information for production execution at required timing. Figure 4 shows a structure of the MSPS execution system.

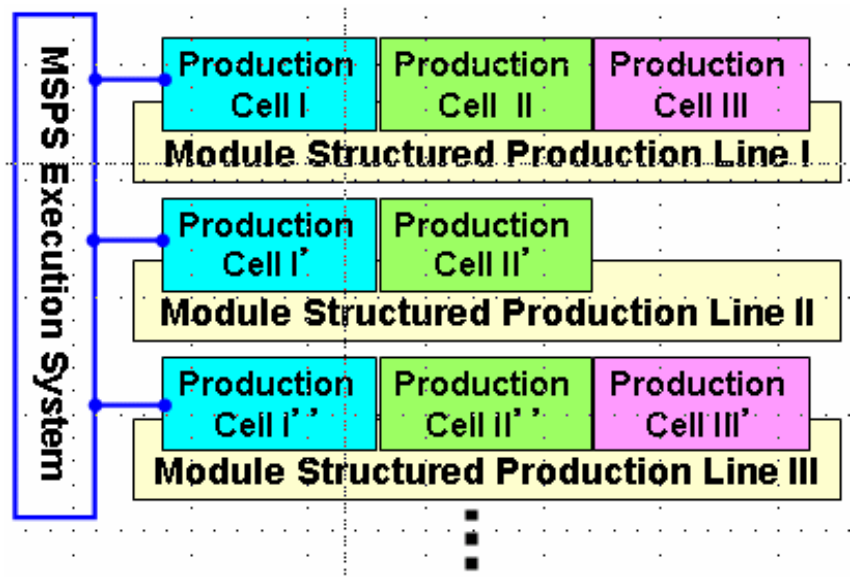

Fig.1 Structure of the MSPS

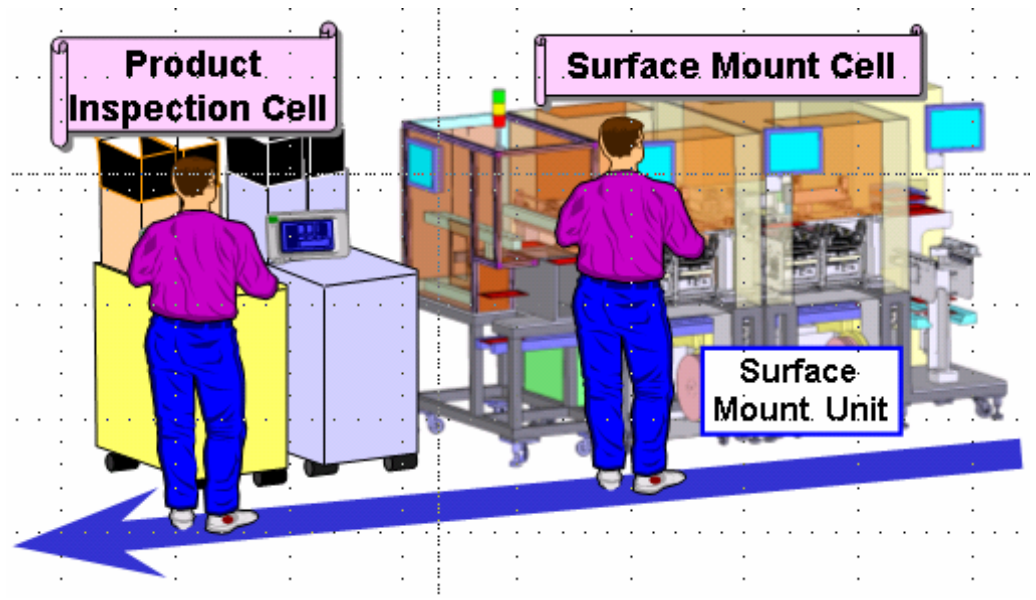

Fig.2 Examples of MSPS

\begin{tabular}{|l|c|c|c|c|}
$\begin{array}{c}\text { Function } \\
\text { Unit (1) }\end{array}$ & $\begin{array}{c}\text { Function } \\
\text { Unit (2) }\end{array}$ & $\begin{array}{c}\text { Function } \\
\text { Unit (3) }\end{array}$ \\
\hline & Production cell I & $\begin{array}{c}\text { Production } \\
\text { Cell II }\end{array}$ & $\begin{array}{c}\text { Production } \\
\text { Cell III }\end{array}$ \\
\hline
\end{tabular}

Fig.3 Structure of production cell in MSPS 


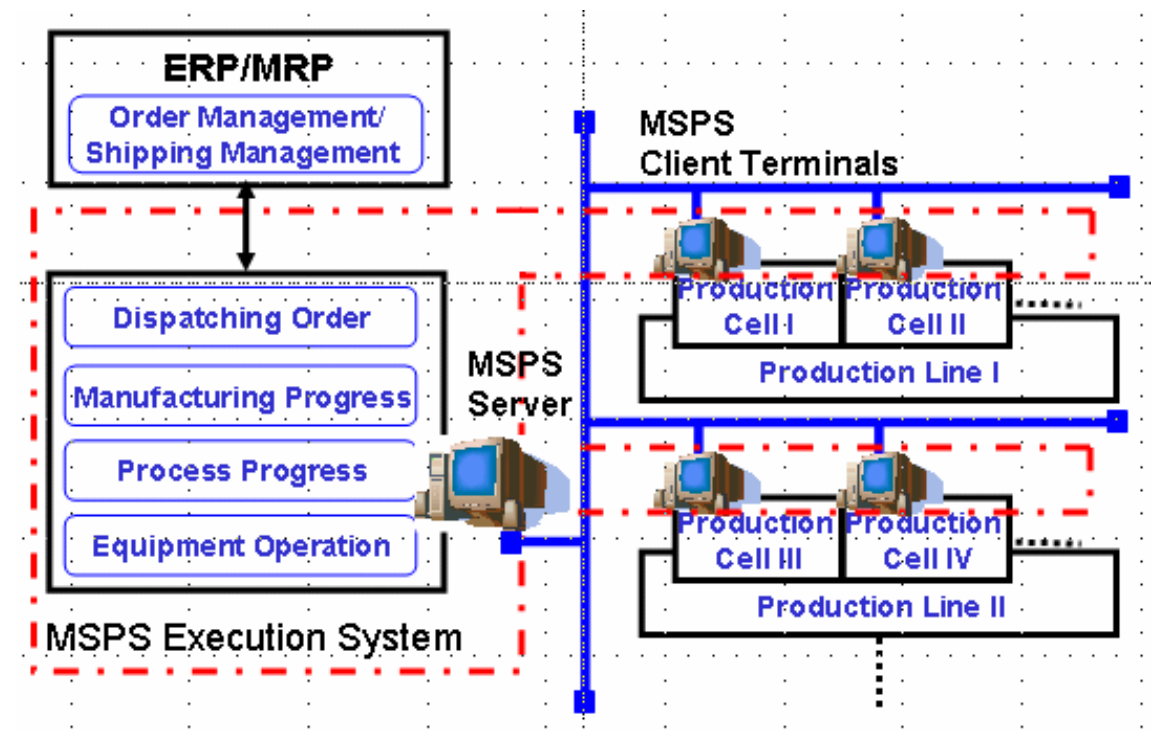

Fig.4 Structure of MSPS execution system

\subsection{Flexible Configuration}

MSPS corresponds to the manufacturing line efficiently while flexibly arranging the production cells using the best function unit in response to the product types. In order to manage MSPS flexibly and efficiently, there are seven patterns to arrange the production cells as shown in Fig. 5.

1) Changing Attributes of the Function Unit

When objective products belong to the same product group, it is general that they have the same shapes but different specifications and performances. For example, when control parameters of assembly cells such as temperature profile of the reflow cell are changed, processing procedure in the cell and conditions of the function unit need to be changed. However, this could be solved by changing attributes of the function unit.

2) Adding More Function Units

When objective products are changed, processing performance of a specific function unit would become insufficient and bring balance-loss in between the previous and next function units. When this happens by adding the same function unit and combining identical several function units, performance of this function unit could be increased and the time balancing between the previous and next function units could be coordinated.

Additional operations or assembly not required before changing product type may be necessary. In this case, addition of new function unit to the appropriate production cell would respond to the change.

3) Removing the Function Unit

On the contrary, of the case 2), by changing the product to be manufactured, performance of the specific function unit would be surplus and bring balance-loss in between the previous and next function units. This time, by removing an exceeded function unit from the function units, performance of this function unit could be decreased and tact balance between previous and next function units could be coordinated.

By changing products, the function unit responsible for operations or assembly that will be unnecessary after the change can be removed.

4) Replacing the Function Unit

When a product to be manufactured is in the same family and only series are different, product shape would largely differ in general. In this case, depending on the 




Fig.5 Flexible production patterns of MSPS

shape, the best elemental operation would be also different. As the function unit is a unit performing single elemental operation, it cannot respond to different elemental operation. This time, replacing the function unit could solve the problem.

5) Adding the Production Cell

When configurations of products and parts are different, change of the function unit would not be sufficient. It is necessary to install production cell matching the configurations into the manufacturing line.

6) Removing the Production Cell

On the contrary of the case 5, optimal manufacturing line for product to be manufactured would be arranged by removing a production cell.

7) Replacing the Production Cell

Furthermore, by replacing a production cell, optimal manufacturing line could be arranged.

\section{Dispatching Order System}

\subsection{Problems and requirements of Demand-Synchronized Production using MSPS}

Generally, in order to be steady for performance of manufacturing line at a certain point, Heijunka (levelized production) of production schedule is done as a mean for effective production synchronizing variable demands (actual orders). However, it is difficult to plan a standardized schedule completely matching the performance of manufacturing lines with variable actual orders. Thus, inconsistency would be resulted.

To solve this inconsistency, we propose MSPS, controlling production performance flexibly by changing manufacturing lines with the seven patterns for matching variable orders and performance. On implementing MSPS to real manufacturing fields, we meet some following problems for operating the system efficiently. 
The first problem is, considerable preparation time would be required due to physical constraints such as setup changes and supplying components at changing the manufacturing lines for the different production cells or the function units that are structural elements of MSPS.

Secondly, in order to make different types of products in one manufacturing line, each cell and line needs to have a setting time in response to arranging the suitable conditions. Frequency and required time of setup change would vary depending on to which manufacturing line order is dispatched. There may be a possibility to decrease manufacturing line performance if inefficient production order is executed.

Furthermore, rush order may be received from customers or some trouble may occur with production facilities such as actual order change or manufacturing line change.

Dispatching order systems that solve the above problems play important roles to realize demand-synchronized production. We propose a dispatching order system which can execute demand synchronized production without changing production schedule. The requirements of the proposed dispatching order system are as follows.

The first requirement is that production order sequence must be considered the setup and preparation time and frequency because of shortening setup and preparation time and reducing frequency of setup.

The second requirement is to decide a production order in quick response as faster as possible while grasping changes of demands and manufacturing lines situations.

\subsection{Configuration and Procedure of Dispatching Order System}

Our proposed dispatching order system is classified into three types of subsystems. One is located in the MSPS server, one is located in the production cell terminal, and one is located in the controllers of function units. Each subsystem transmits/receives data at real time and executes essential processing. The configuration of dispatching order system is shown in Fig. 6.

A typical procedure in our proposed system is following.

A) An order is acquired from the order information storage of the MSPS execution system.

B) Order-dispatching requests in response to the order are made. The request consists of order information to each production cell and evaluation parameters.

C) Requests are sent to each production cell. The production cell receives the requests.

D) The direction is sent to the subsystem in a suitable function unit for calculating the evaluation values for the request.

E) The information that includes setup time and cycle time considering cell configurations is acquired from production order storage in the cell subsystem. Then evaluation value is calculated in the subsystem in the function unit.

F) The calculation results which include the evaluation values and load capacity in each cell are sent to the subsystem in the cell.

G) The reports based on the calculation results are sent to the subsystem in the server. Finally, the server determines which manufacturing line is suitable for the order and decides the dispatching order.

H) The dispatching order is sent to the acceptance part of the subsystem in the cell.

I) The production cell updates dispatching order information according to the new received dispatching order.

The above processes indicated with alphabets correspond to those in Fig. 6. 


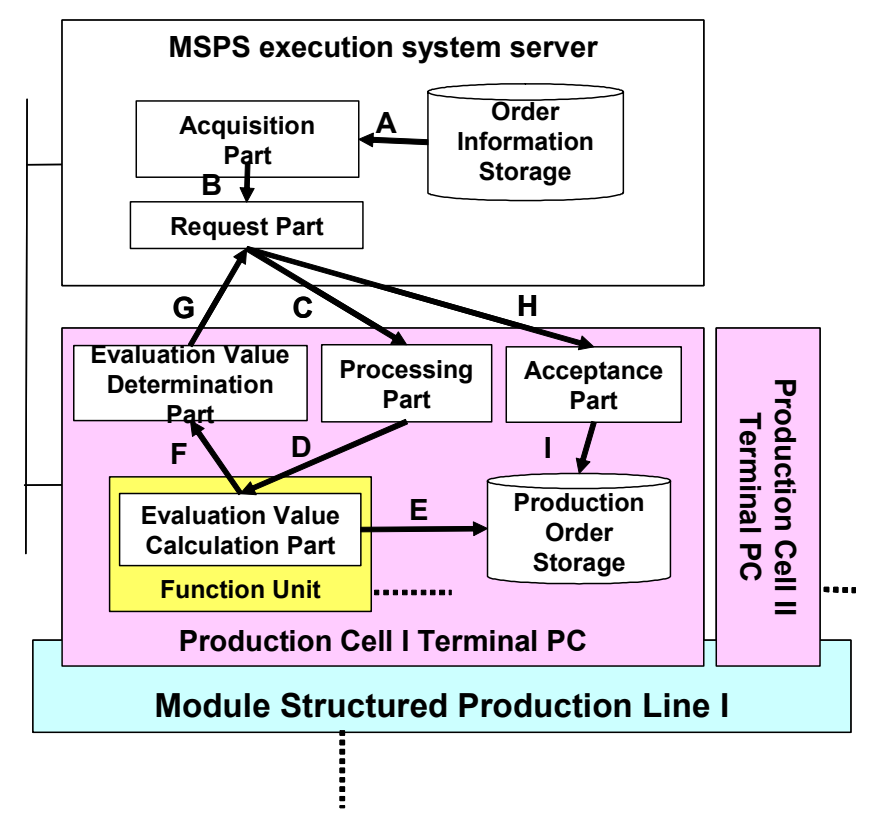

Fig.6 Composition of the proposed dispatching order system

\subsection{Operation Flow of Dispatching Order System}

Figure 7 shows daily operational flow. On the beginning of the day, dispatching order information due today is provided to the production line. This dispatching order information is defined as normal order information. Then, today's operation starts according to the normal information. Sequences to the applicable production cell consisting of manufacturing lines by the time of starting production and dispatching of normal order are executed. After the normal order is dispatched, the manufacturing line starts operation. The dispatching process of the normal order starts with transmission of the order information and the evaluation parameters. In another words, before the operation time to start each production, the order acquisition part of the MSPS server reads the normal orders due today from the order information storage. The normal orders are dispatched. This process is repeated until all normal orders due today are dispatched and every normal order to be executed at each manufacturing line is determined by the time of start of operation. The normal orders determined are stored in each production cell as a production sequencing list shown in Table 1.

The evaluation values for production cell are calculated by the evaluation calculation methods described in the later section according to the production sequence list. The evaluation values for each manufacturing line are determined based on the evaluation values calculated at each production cell. The MSPS server compares the evaluation values calculated at all the manufacturing lines applicable for the production sequencing list, and determines which manufacturing line is suitable to produce the production sequencing list. Each manufacturing line is dispatched the orders on the production sequencing list as the normal orders.

During the operation, manufacturing line can accept rush orders newly received from customer. The acquisition part accesses the order information storage to check whether there is a rush order periodically. If there is rush order information in the storage, the acquisition part dispatches the individual rush order in the same way of dispatching the normal orders. The procedure of rush order is executed while each manufacturing line manufactures with the production sequencing list.

Furthermore, when there is a delay in progress due to some trouble, the production cell checks the production sequencing list and it determines difficult to complete the order within the day, it requests dispatching of rush order. 


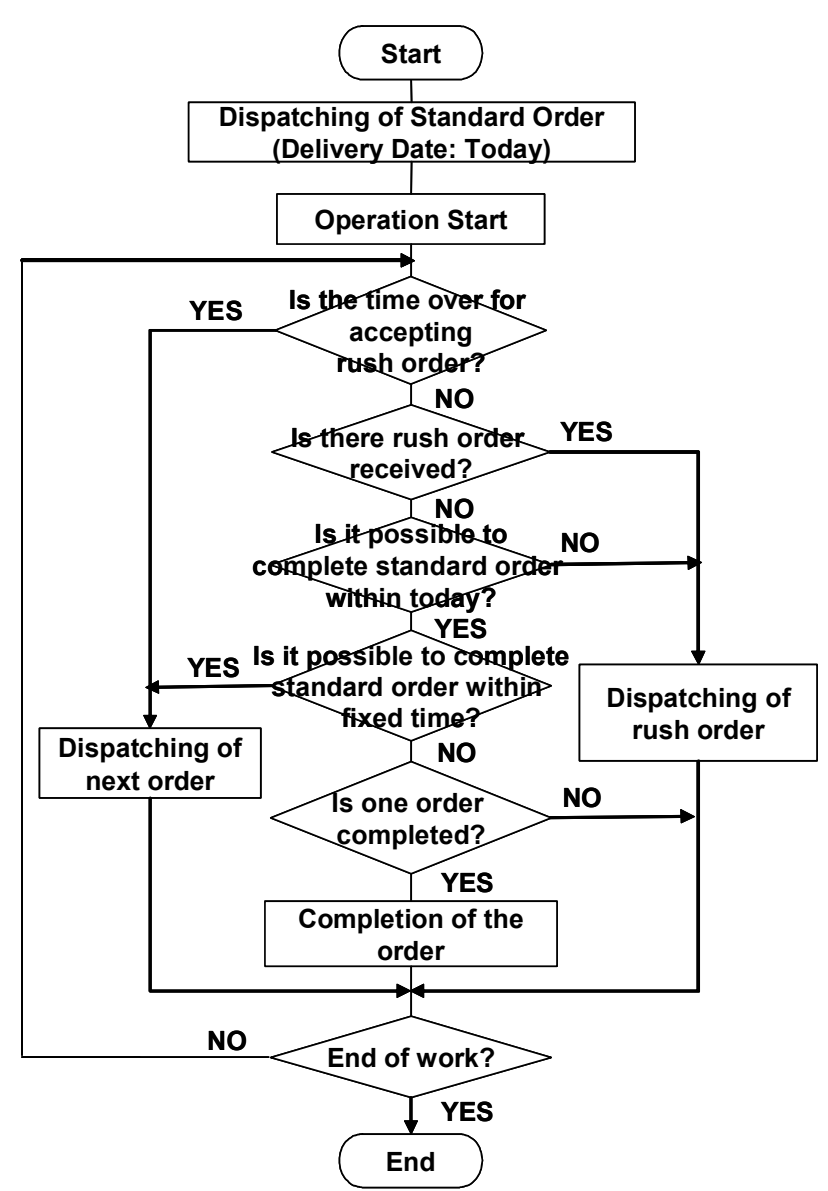

Fig.7 Daily operation flow

Table1 Example of production sequencing list

\begin{tabular}{c|c|c|c|c}
\hline $\begin{array}{c}\text { List } \\
\text { No. }\end{array}$ & $\begin{array}{c}\text { Order } \\
\text { No. }\end{array}$ & $\begin{array}{c}\text { Production } \\
\text { item }\end{array}$ & $\begin{array}{c}\text { Production } \\
\text { Volume } \\
\text { (unit) }\end{array}$ & Due Date \\
\hline 1 & M001 & A & 10 & Today \\
\hline 2 & M002 & A & 20 & Today \\
\hline 3 & M011 & B & 5 & Today \\
\hline 4 & M012 & B & 1 & Today \\
\hline 5 & M111 & C & 35 & Today \\
\hline
\end{tabular}

\subsection{Calculation Method of Evaluation Values}

After each production cell receives order-dispatching request, it forwards the request to the function unit consisting of the applicable production cell. Each function unit chooses product model and evaluation parameters from the order-dispatching request information received. The production cell decides the production sequence as a temporary production sequencing list shown in Table 1. It refers to the database as shown in Table 2 to determine in which the order could be put for optimization of the evaluation parameters indicated by order-dispatching request information and calculates the evaluation values in the function unit. In the example, the time required to change setups for a different order in the function unit is defined as a matrix shown in Table 2. When the order of the different product model is changed from the one on "Before" to that on "After," the Table 2 shows which the pattern (Fig. 5) is required for the setup change at each production cell and function unit and how long it is required. For example, the time required for a change from Model $\mathrm{A}$ to $\mathrm{C}$ at a 
Table2 Change Patterns and Required Time

\begin{tabular}{|c|c|c|c|c|}
\hline Before & $\begin{array}{c}\text { Production } \\
\text { item A }\end{array}$ & $\begin{array}{l}\text { Production } \\
\text { item B }\end{array}$ & $\begin{array}{l}\text { Production } \\
\text { item C }\end{array}$ & $\begin{array}{c}\text { Production } \\
\text { item D }\end{array}$ \\
\hline $\begin{array}{l}\text { Production } \\
\text { item A }\end{array}$ & & $\begin{array}{c}\text { Pattern } 1 \\
30(\mathrm{sec})\end{array}$ & $\begin{array}{l}\text { Pattern } 2 \\
300 \text { (sec) }\end{array}$ & $\begin{array}{l}\text { Pattern } 4 \\
500 \text { (sec) }\end{array}$ \\
\hline $\begin{array}{l}\text { Production } \\
\text { item B }\end{array}$ & $\begin{array}{l}\text { Pattern } 1 \\
30(\mathrm{sec})\end{array}$ & & $\begin{array}{c}\text { Pattern 1\&2 } \\
330(\mathrm{sec})\end{array}$ & $\begin{array}{l}\text { Pattern } 4 \\
500 \text { (sec) }\end{array}$ \\
\hline $\begin{array}{l}\text { Production } \\
\text { item C }\end{array}$ & $\begin{array}{l}\text { Pattern } 3 \\
200 \text { (sec) }\end{array}$ & $\begin{array}{c}\text { Pattern 1\&3 } \\
230 \text { (sec) }\end{array}$ & & $\begin{array}{c}\text { Pattern 3\&4 } \\
700 \text { (sec) }\end{array}$ \\
\hline $\begin{array}{c}\text { Production } \\
\text { item D }\end{array}$ & $\begin{array}{l}\text { Pattern } 4 \\
500 \text { (sec) }\end{array}$ & $\begin{array}{l}\text { Pattern } 4 \\
500 \text { (sec) }\end{array}$ & $\begin{array}{c}\text { Pattern } 2 \& 4 \\
800(\mathrm{sec})\end{array}$ & \\
\hline
\end{tabular}

certain function unit is 300 seconds that from Model B to C is 330 seconds. In this way after each function unit calculates evaluation values, the production cell totals all the evaluation values from the function units and calculates evaluation values of the entire production cell.

\subsection{Features of Dispatching Order System}

The feature of the proposed dispatching order system has four features.

The first feature is that multiple parameters can be set and chosen reflecting requirements of customers and production departments. As the first priority of customer's requirements is usually to keep the delivery date, it would be important to minimize balance-loss among the production cells. Therefore, by calculating the evaluation values of idling time among the production cells as the highest priority parameter, it is possible to dispatch the order to the line that can complete production at the earliest time. When operation efficiency of the line is considered to important, it is possible to dispatch the order to the line, which can produce without loss of setup changes by calculating time required for setup changes as the highest priority parameter.

As the second feature, the production cell that has more production capacity at the current time requests the additional order to be produced to the order dispatching system. Therefore, it could prevent the production cells from being not operated for a long time and the efficiency of the entire manufacturing line could be increased. These two features solve the problems of the production dispatching for demand-synchronized production effectively.

The third feature is the following. Our proposed dispatching order system is classified into three types of subsystems. One is located in the MSPS server, one is located in the production cell terminal, and one is located in the controllers of function units. Each subsystem transmits/receives data at real time and executes essential processing. Different from standard client-server system, a distributed system that does not bring load in the server is established. In addition, as there is no adjustment procedure among manufacturing lines and it is different from general autonomous distributed system, process load in each production cell would be lighter. This could bring order dispatching in short time when a number of order is increased dramatically or with a large-scale MSPS consisting of many manufacturing lines and cells.

The fourth feature is that receiving rush order is executed while each manufacturing line manufactures with the production sequencing list. Efficiency of the entire manufacturing line could be improved by flexibly responding to the variable conditions and by dispatching efficient orders during operation time. 
Table3 Experimental conditions

\begin{tabular}{|c|c|c|}
\hline & Item & Value \\
\hline & duction Period & 10 (days) \\
\hline & nber of Production Lines & 10 (lines) \\
\hline & Production Item & 1,077 (items) \\
\hline 产 & Number of Order & 38,230 (orders) \\
\hline 产 & Production Volume / Order & $1 \sim 3,500$ (units) \\
\hline$\stackrel{?}{0}$ & Total Production Volume & 595,754 (units) \\
\hline$\frac{9}{6}$ & $\begin{array}{l}\text { Lead Time from Order to } \\
\text { Due Date }\end{array}$ & $1 \sim 60$ (days) \\
\hline
\end{tabular}

Table4 Experiment result

\begin{tabular}{l|r|r}
\hline Evaluation Item & \multicolumn{1}{|c|}{$\begin{array}{c}\text { Scheduler } \\
\text { System }\end{array}$} & $\begin{array}{c}\text { The Dispatching } \\
\text { Order System }\end{array}$ \\
\hline Operation Rate & $89.4(\%)$ & $93.7(\%)$ \\
\hline Standard Deviation & 1.18 & 0.94 \\
\hline Delayed Order & 12 (num) & 1 (num) \\
\hline Delayed Unit & 924 (units) & 377 (units) \\
\hline
\end{tabular}



Fig.8 Results of experiment

Table5 Experimental conditions for rush order productions

\begin{tabular}{|c|c|c|}
\hline & Item & Value \\
\hline & duction Period & 3 (days) \\
\hline $\mathrm{Nu}$ & nber of Production Line & $3 \sim 10$ (lines) \\
\hline & Production Item & 1,257 (items) \\
\hline$\overbrace{\infty}^{D}$ & Number. of Order & 6,580 (orders) \\
\hline$\sigma_{0}^{5}$ & Production Volume / Order & $1 \sim 1,330$ (units) \\
\hline$\frac{2}{9}$ & Total Production Volume & 74,536 (units) \\
\hline & Lead Time from Order to Due Date & 1 (day) \\
\hline
\end{tabular}




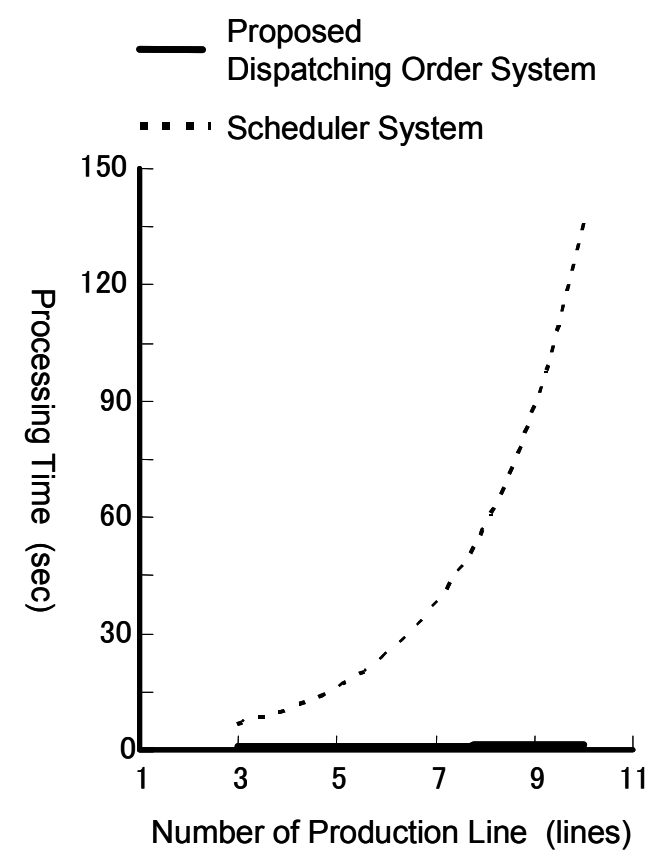

Fig.9 Results of processing time on computer

\section{Evaluation of Dispatching Order System}

We evaluated performance of dispatching order system in the viewpoint of effectiveness and response meeting the delivery date comparing a commercial production scheduler and dispatching order system. The priority of both systems is meeting the delivery date.

First, we compared effectiveness of the system. As discussed before, the dispatching order system needs to be flexible to variable orders. In other words, order should be dispatched enabling highly efficient performance of manufacturing lines by controlling setup changes for meeting the preferred delivery date from customers. The number of late delivery and average operation rate were evaluated as system effectiveness. We made experimental conditions shown in Table 3 and obtained the results shown in Table 4 and Fig. 8. From these results, the dispatching order system is found to be no inferior compared with the production scheduler. The dispatching order system maintains high efficiency of the manufacturing lines limiting number of late delivery orders with satisfying preferred delivery date from customers. This means the production cells determine production order with efficient possible setup changes. Furthermore, the production orders with a small standard deviation within a day in the target period are possible. This means the orders are dispatched being not influenced by variability of the actual daily order.

Secondary, we compared system response of both systems. As discussed in the former section, the dispatching order system is executed frequently during operation. Depending on the size of MSPS (the number of manufacturing lines), number of the actual orders, frequency of the rush orders could extend time to decide the dispatching orders. Therefore, response time to the dispatch orders is expected to be as short as possible. When the rush orders are accepted during operation and have to be dispatched; system's response performance is evaluated with the processing time per order when the number of the applicable manufacturing lines are changed. For this evaluation, we made an experiment with the conditions shown in Table 5 and obtained the results shown in Fig. 9. From the results of Fig. 9, the processing time of the orders dispatching by the production scheduler took longer in an exponential manner as the number of the manufacturing lines increased. On the other hand, the processing time of the order dispatching system stayed constant as 
close as zero. This means that the processing time does not rely on the number of the orders or the manufacturing lines in the system proposed. When the rush orders are dispatched during operation, it is considered there would be little possibility that the processing time significantly deteriorated by the conditions of the manufacturing lines. Compared to the production scheduler, the dispatching order system was confirmed to have an advantage on response performance.

This is because the dispatching order system is executed decentrally in the server and each production cell. As it is a distributed system, the target order and manufacturing lines were limited at each subsystem and its process decreased. For example, when the rush orders are dispatched to an operating production system of ten lines, the production scheduler resets production orders already fixed at all the manufacturing lines; the processing of significant load would be required. On the other hand, the dispatching order system considers condition of each production cell and decides to which line rush order should be dispatched.

From these results of two experiments, the dispatching order system based on MSPS is esteemed as an effective ordering method enabling synchronized manufacturing for various demands from customers.

\section{Conclusion}

We explained an optimal configuration and an order dispatching system that dispatches production order to manufacturing lines with synchronizing customers' various demands on MSPS in base. The dispatching order system consists of processing parts implemented in the MSPS server and production cells and subsystems implemented decentrally in the function units. The system provides a suitable configuration that dispatches production orders by transmitting necessary data and is effective in the viewpoint of response performance by flexibly responding to the manufacturing lines. For a method to determine production orders, there are two effective methods; standard-order-dispatching and rush-order-dispatching which is executed when rush order is received. With the system we proposed using the two order dispatching methods discussed above efficiently, an outstanding dispatching order system could be realized by high efficient operation of manufacturing lines responding to customers' various demands based on MSPS.

This research results intended for the industrial component equipment showed the possibility of synchronous demand production that observed customer's preferred delivery date and made the stock of finished goods minimum until several days.

\section{References}

(1) Tanaka, K., Hibino, H., Fukuda, Y., Module Structured Production System, The International Journal of Manufacturing Systems, CIRP, (2008), pp.303-308

(2) Fujii, S.; Kaihara, T.; Sashio, K.; Yokose, H.; Kurahashi, M., Hayashi, N., A Basic Study of Auction-based Planning and Scheduling for Cell Manufacturing, Lean business systems and beyond, (2006), pp. 55-60

(3) Mehrabi, M. G., Ulsoy, A., G., et al., Reconfigurable Manufacturing Systems, Key to Future Manufacturing, Journal of Intelligence Manufacturing, Vol.11, No.4, (2000), pp.403-419

(4) Molina, A., Rodriguez, C.A., et al., Next-generation manufacturing systems: key research issues in developing and integrating reconfigurable and intelligent machines, International Journal of Computer Integrated Manufacturing, Vol.18, No.7, (2005), pp.525-536

(5) Nakatsuka, N., Fukuda, Y., et al. Development and Operation of a Synchronized Production System Using a Virtual Production Concept, Journal of Japan Industrial Management Association, Vol.57, No.4, (2006), pp.272-277 